\title{
Totem e Tabu: uma "semiologia psicanalítica" em Freud?"
}

\author{
Totem and Taboo: a Freud's "psychoanalytical semiology"?
}

\author{
Victor Eduardo Silva BENTO2
}

\begin{abstract}
Resumo
O tema deste artigo é a pesquisa de revisão sobre a seguinte questão: quais seriam os fundamentos freudianos para uma "semiologia psicanalítica" e para o método de pesquisa de revisão de literatura em psicanálise? Foi discutida a hipótese de que "Totem e Tabu" constituiu a primeira semiologia psicanalítica de Freud, pois, ainda que Freud não tenha nessa obra se utilizado dessa expressão, pareceu ter ali feito a prática da semiologia psicanalítica dos dois signos: "Totem" e"Tabu". Concluiu-se que, para manter uma ótica psicanalítica freudiana num estudo semiológico, seria necessário enfatizar a análise radical dos universais da linguagem - reveladores da natureza humana profunda -, do psiquismo inconsciente do homem, extraindo tais universais, num primeiro tempo, dos totens e mitos, mas, também, num segundo tempo, dos tabus e das religiões. A demanda pelo exame de "escritos" pareceu, assim, justificar o método de revisão de literatura em psicanálise.
\end{abstract}

Unitermos: Freud; semiologia psicanalítica; revisão de literatura; psicanálise; totem; tabu.

\begin{abstract}
This paper focus is a review about the Freudian issues about a psychoanalytical semiology and a research method of lecture review. The hypothesis that "Totem and Taboo" is the first Freud's psychoanalytical semiology has been discussed. Though Freud did not use such a term, it was argued that Freud did in this book the psychoanalytical semiology of the two signs: "Totem" and "Taboo". This paper concluded that in order to do a semiological study, it would be necessary to emphasize the analysis of the universal language patterns which reveal the deepest human nature and the unconscious psychism. Such analysis should be done in two different phases: the first one, seeking those patterns within the totems and myths; the second one, seeking the same patterns within the taboos and religions. This kind of study requires writings survey, and justifies the use of literature review as psychoanalytical method in.
\end{abstract}

Uniterms: Freud; psychoanalytical semiology; literature review; psychoanalysis; totem; taboo.

Trata-se aqui de pesquisa teórica em torno das seguintes questões: quais seriam os fundamentos freudianos para uma"semiologia psicanalítica"e para o método de pesquisa de revisão de literatura em psicanálise? Seria a obra de nome "Totem e Tabu" uma "semiologia psicanalítica" em Freud (1913/1974)? Se sim,
seria"Totem e Tabu"um fundamento para o método de pesquisa de revisão de literatura em psicanálise? Logo, o objetivo do presente estudo será discutir essas questões, por meio do método de revisão de literatura. Essa será, então, uma pesquisa de revisão da literatura psicanalítica para justificar o método de "revisão de

\section{$\boldsymbol{\nabla v \boldsymbol { V }}$}

1 Artigo elaborado a partir da tese de V.E.S. BENTO, intitulada "La passion amoureuse'toxique': une approche psychanalytique a partir de la sémiologie et du narcissisme chez Freud". Université Paris 7, 1996.

2 Universidade Federal do Rio de Janeiro, Instituto de Psicologia, Departamento de Psicometria. Av. Pasteur, 250, Pavilhão Nilton Campos, Praia Vermelha, 22290-240, Rio de Janeiro, RJ, Brasil.E-mail:<victorbento@oi.com.br>. 
literatura" em psicanálise e construir o que se denomina aqui de semiologia psicanalítica como método de pesquisa teórica em psicanálise, valorizando principalmente as contribuições de Freud.

Mas de onde surgiu a idéia de estudar tal problema? Como justificar a importância deste problema e de seu estudo? Mais precisamente, caberiam ser colocadas as seguintes questões específicas: 1) Por que buscar fundamentos em Freud para uma semiologia psicanalítica? 2) Por que colocar em questão o método de pesquisa de revisão de literatura em psicanálise? e 3) Por que relacionar num mesmo problema a semiologia psicanalítica e a revisão de literatura no contexto da pesquisa psicanalítica? Pretende-se, a seguir, discutir essas questões.

A idéia de estudar o problema principal desta pesquisa surgiu por ocasião da preparação da tese de doutorado do autor deste estudo (Bento, 1996). Tratavase de uma tese baseada fundamentalmente no método de pesquisa de revisão de literatura, no contexto de um doutorado em Psicopatologia Fundamental e Psicanálise na Universidade Paris 7. O problema que se colocou desde o início foi como justificar um método que valorizava essencialmente o plano teórico, em oposição à proposta principal da psicanálise, que, como se sabe, destaca, principalmente, a dimensão clínica. Mais precisamente, o problema consistiu em buscar fundamentos psicanalíticos para o método de pesquisa de revisão de literatura, o que culminou na construção de um método de pesquisa que foi chamado pelo autor do presente estudo de semiologia psicanalítica. Mas como se chegou a tal proposição metodológica e a uma tal denominação? Pretende-se a seguir relatar os antecedentes históricos do problema desta pesquisa, identificando as influências teóricas que levaram à proposição dessa semiologia psicanalítica.

Em primeiro lugar, é preciso esclarecer que Freud não propõe diretamente nenhuma semiologia psicanalítica. A primeira fonte de inspiração de Bento (1996) para tal proposição não foi Freud. Foi Saussure (1916/ 1995a, 1916/1995b) e, mais precisamente, sua semiologia im proposta no campo da lingüística, que exerceu a 员 primeira influência em Bento (1996) nessa construção ồ metodológica. Saussure assim define sua semiologia:

Pode-se, então, conceber uma ciência que estude a vida dos signos no seio da vida social; ela constituiria uma parte da Psicologia social e, por conseguinte, da Psicologia geral; chamá-la-emos de Semiologia (do grego semeîon,'signo'). Ela nos ensinará em que consistem os signos, que leis os regem. Como tal ciência não existe ainda, não se pode dizer o que será; ela tem direito, porém, à existência; seu lugar está determinado de antemão. A Lingüística não é senão uma parte dessa ciência geral; as leis que a Semiologia descobrir serão aplicáveis à Lingüística e esta se achará dessarte vinculada a um domínio bem definido no conjunto dos fatos humanos.

Cabe ao psicólogo determinar o lugar exato da Semiologia (Saussure, 1916/1995b, p.24).

Para precisar o que chama de "signo", Saussure (1916/1995b, p.80) escreverá:"o signo lingüístico une não uma coisa e uma palavra, mas um conceito (significado) e uma imagem acústica (significante)". Além disso, tratarse-á para esse autor de valorizar uma dimensão psíquica, pois, segundo ele, a imagem acústica não é "o som material, coisa puramente física, mas a impressão (empreinte) psíquica desse som, a representação que dele nos dá o testemunho de nossos sentidos". É o que fará da semiologia, a ciência dos signos, uma psicologia. A semiologia, escreve Saussure (1916/1995b, p.24): "constituiria uma parte da Psicologia social e, por conseguinte, da Psicologia geral".

E para detalhar aquilo que Saussure (1916/1995b, p.24) chama de"social", de"vida social", este autor evocará "um domínio bem definido no conjunto dos fatos humanos", ilustrando-os pelos "ritos, os costumes etc".

Depois de Saussure, outra inspiração de Bento (1996) para a construção do método da "semiologia psicanalítica" foi Lévi-Strauss (1958/1974; 2003) e sua antropologia estrutural. Por um lado, Lévi-Strauss evoca a lingüística de Saussure, ainda que para criticá-la, mais precisamente para se opor ao fato de Saussure, segundo ele, ter restringido sua abordagem ao arbitrário do signo, a dimensão relativa do social, aos sistemas particulares de signos. Ao criticá-lo, Lévi-Strauss justificara, por outro lado, sua proposição dos mitos como sendo universais lingüísticos (Bento, 1996), ausentes no pensamento de Saussure. Lévi-Strauss justificará sua hipótese dos mitos como sendo os reveladores do inconsciente humano apoiando-se em Freud e na psicanálise, quando escreve:

Pensamos particularmente na noção de mito e na noção de inconsciente. ... De fato, inúmeros psicanalistas se recusarão a admitir que as constelações psíquicas que reaparecem à consciência do doente possam constituir um mito" (Lévi-Strauss, 2003, p.233). 
... o objeto próprio dos mitos é de oferecer uma derivação a sentimentos reais, mas recalcados (LéviStrauss, 2003, p.239).

A partir, então, de Saussure (1916/1995a, 1916/ 1995b) e de Lévi-Strauss (1958/1974, 2003), as duas primeiras inspirações de Bento (1996) para propor a "semiologia psicanalítica" tratada neste trabalho, chegou-se à noção de um método de pesquisa que estudaria os signos no seio de sua vida social, entendose "social" como remetendo ao contexto dos ritos, dos costumes, dos mitos universais, dos escritos clássicos, etc. Tal estudo permitiria o acesso aos sistemas de signos particulares (nas línguas) e universais (nos mitos), linguagens reveladoras da natureza humana mais profunda, do psiquismo inconsciente do homem. Não se poderia ver aqui um modelo de método de pesquisa que, valorizando a linguagem como legado social, daria importância a sua dimensão "escrita" (nos mitos, nas lendas, nos escritos clássicos, etc.), e, assim, funcionaria como justificativa da revisão de literatura? Por outro lado, a idéia dessa linguagem escrita revelar o psiquismo inconsciente do homem não permitiria supor que tal método de pesquisa justificaria, em particular, a revisão de literatura em psicanálise?

Foi questionado acima: Por que buscar fundamentos em Freud para uma "semiologia psicanalítica"? Por um lado, pela pretenção de realizar no presente estudo uma abordagem de inspiração psicanalítica e, por outro, pelo fato de que Freud não propôs diretamente uma semiologia psicanalítica; justamente uma tal carência não justificaria uma busca de indicações indiretas desse autor para que se pudesse, assim, encontrar fundamentos freudianos que servissem para a construção de uma semiologia psicanalítica. A hipótese que será discutida a seguir, neste trabalho, é que "Totem e Tabu" constituirá a primeira "semiologia psicanalítica" de Freud (1913/1974), pois, ainda que o pai da psicanálise não tenha se utilizado dessa expressão na obra em questão, parecerá ter efetivamente ali feito o que se entende como sendo a prática da semiologia psicanalítica de dois signos: "Totem" e"Tabu".

Também foi interrogado acima: por que colocar em questão o método de pesquisa de revisão de literatura em psicanálise? Trata-se aqui de um método de pesquisa encontrado na psicanálise, desde Freud, em "Totem e Tabu", por exemplo, ainda que não seja devidamente valorizado na literatura psicanalítica da atualidade. Talvez pelo fato de a psicanálise ser uma disciplina essencialmente clínica, os autores têm dado preferência ao estudo do método de pesquisa chamado estudo de caso na pesquisa psicanalítica. De fato, são inúmeras as referências bibliográficas a respeito do estudo de caso, e são escassos, na literatura psicanalítica atual, os trabalhos sobre o método de revisão de literatura em psicanálise, carência essa que parece justificar o investimento nessa área.

Ainda se colocou em questão acima: por que colocar em uma mesma questão a semiologia psicanalítica e a revisão de literatura, no contexto da pesquisa psicanalítica? Como já foi adiantado acima, e se verá mais claramente no desenvolvimento deste trabalho, hipotetiza-se que seja precisamente o que se denomina aqui de semiologia psicanalítica o modelo segundo o qual se poderá justificar a revisão de literatura como método de pesquisa em psicanálise.

Para finalizar esta introdução, caberia ainda definir o que se entenderá por método ao longo da presente pesquisa, já que é o método de pesquisa de revisão de literatura em psicanálise, a partir da semiologia psicanalítica, que será a seguir colocado em discussão.

Por método, entende-se, juntamente com o Novo Dicionário Aurélio:

1. Caminho pelo qual se chega a um determinado resultado, ainda que esse caminho não tenha sido fixado de antemão de modo deliberado e refletido. 2. Programa que regula previamente uma série de operações que se devem realizar, apontando erros evitáveis, em vista de um resultado determinado (Ferreira, 1975, p.919).

No Vocabulário Técnico e Crítico da Filosofia, Lalande proporá uma definição de método, no seu sentido "A", muito semelhante a essa de Ferreira acima em destaque, porém com maior detalhamento, como segue:

A. Etimologicamente, 'demanda' ...; e, por conseqüência, esforço para atingir um fim, investigação, estudo ...; de onde nos modernos, duas acepções muito próximas, ainda que possíveis de distinguir.

10) Caminho pelo qual se chegou a determinado resultado, mesmo quando esse caminho não foi previamente fixado de uma maneira premeditada e refletida. 'Chama-se aqui ordenar à ação do espírito pela qual, tendo sobre um mesmo assunto... diversas 
idéias, diversos juízos, diversos raciocínios, ele os dispõe de maneira mais adequada para conhecer esse assunto. É o que também se chama método. Tudo isso se faz naturalmente e algumas vezes melhor por aqueles que não aprenderam qualquer lógica do que por aqueles que as aprenderam.'Lógica de Port-Royal, introdução, 6-7.

Esta palavra diz-se muitas vezes, neste sentido, dos processos habituais de um espírito ou de um grupo de espíritos, processos que se podem observar e definir por indução, quer para em seguida os praticar mais seguramente, quer para os criticar e mostrar a sua invalidade.

$2^{\circ}$ ) Programa que regula antecipadamente uma seqüência de operações a executar e que assinala certos erros a evitar, com vista a atingir um resultado determinado" (Lalande, 1996, p.678).

Pode-se agora discutir o problema central desta pesquisa.

\section{"Totem e Tabu": uma semiologia psicanalítica em Freud (1913/1974)?}

Se os três cursos de lingüística geral de Saussure aconteceram respectivamente em 1906-1907, 1908-1909 e 1910-1911, antes de sua primeira publicação em 1916, Freud publicará em 1913 um estudo correspondendo, na prática, ao modelo de semiologia idealizado por Saussure (1916/1995a, p.32). Tratava-se, mais precisamente, de "Totem e Tabu", onde, desde as primeiras linhas do seu primeiro capítulo, Freud escrevia:

O homem pré-histórico, nas várias etapas de seu desenvolvimento, nos é conhecido através dos monumentos e implementos inanimados que restaram dele, através das informações sobre sua arte, religião e atitude para com a vida - que nos chegaram diretamente ou por meio de tradição transmitida pelas lendas, mitos e contos de fadas -, e através das relíquias de seu modo de pensar que sobrevivem em nossas maneiras e costumes. À parte disso, porém, num certo sentido, ele ainda é nosso contemporâneo. Há homens vivendo em nossa época que, acreditamos, estão muito próximos do homem primitivo, muito mais do que nós, e a quem, portanto, consideramos como seus herdeiros e representantes diretos. Esse é o nosso ponto de vista a respeito daqueles que descrevemos como selvagens ou semiselvagens; e sua vida mental deve apresentar um interesse peculiar para nós, se estamos certos quando vemos nela um retrato bem conservado de um primitivo estágio de nosso próprio desenvolvimento.

Se essa suposição for correta, uma comparação entre a psicologia dos povos primitivos, como é vista pela antropologia social, e a psicologia dos neuróticos, como foi revelada pela psicanálise, está destinada a mostrar numerosos pontos de concordância e lançará nova luz sobre fatos familiares às duas ciências (Freud, 1913/1974, p.20).

A proposição que aparece aqui é a de estudar dois signos - "totem" e"tabu" - a partir das lendas, mitos e contos de fadas do homem primitivo, justificada pela suposição que tal iniciativa permitiria revelar uma verdade humana imutável, atemporal, pois:"num certo sentido, ele (o homem pré-histórico) ainda é nosso contemporâneo". Esta proposição de Freud (1913/1974) não corresponderia, na prática, àquela semiologia que Saussure (1916/1995b, p.24) idealizou como"ciência que estude a vida dos signos no seio da vida social", esse "social" compreendido como"um domínio bem definido no conjunto dos fatos humanos" - esses fatos ilustrados pelos "ritos, os costumes, etc."?

Freud (1913/1974, p.20) proporá também uma psicologia dos povos primitivos "a partir de uma comparação entre esta," como é vista pela antropologia social, e a psicologia dos neuróticos, como foi revelada pela psicanálise". Essa idéia de uma psicologia dos povos primitivos não revelaria uma outra aproximação da semiologia de Saussure (1916/1995b, p.24), concebida como sendo "uma parte da Psicologia social?" Essa comparação de Freud não remeteria a uma noção de semiologia abordada segundo uma ótica psicanalítica? Se sim, caberia levantar a questão: teria Freud recebido a influência de Saussure, especialmente ao realizar esse estudo dos signos "Totem" e"Tabu"?

Já que se trata de colocar a questão de saber quais teriam sido as influências teóricas, os pressupostos epistemológicos, no Freud (1913/1974) de "Totem eTabu", caberia evocar, em primeiro lugar, aquilo que o próprio Freud declara a esse respeito desde as primeiras linhas do prefácio à primeira edição dessa obra, onde escreve:

Os quatro ensaios que se seguem foram originalmente publicados (sob um título que serve de subtítulo ao presente livro) nos dois primeiros volumes de Imago, periódico editado sob a minha direção. Representam uma primeira tentativa de minha parte de aplicar o ponto de vista e as 
descobertas da psicanálise a alguns problemas não solucionados da psicologia social [Völkerpsychologie]. Dessa maneira, apresentam, por um lado, um contraste metodológico com a obra de Wilhelm Wundt, que aplica as hipóteses e os métodos de trabalho da psicologia não-analítica aos mesmos objetivos, e, por outro, com os trabalhos da escola de psicanálise de Zurique, que se esforça, pelo contrário, por solucionar os problemas da psicologia individual com o auxílio de material derivado da psicologia social. (Cf. Jung, 1912; 1913). Apresso-me em confessar que foi dessas duas fontes que recebi o primeiro estímulo para os meus próprios ensaios.

Estou plenamente consciente das deficiências destes estudos.... Estes ensaios procuram diminuir a distância existente entre os estudiosos de assuntos como a antropologia social, a filologia e o folclore, por um lado, e os psicanalistas, por outro" (Freud, 1913/1974, p.17).

Pode-se ver acima que Freud destacará a lingüística, ao se referir à filologia, que, segundo Ferreira (1975, p.629), é o "estudo da língua em toda a sua amplitude, e dos documentos escritos que servem para documentá-la". Na tradução francesa dessa mesma obra será o termo "linguistes" (Freud, 1913/1965, p.8) que aparecerá diretamente referido. Vê-se ainda que o objetivo dessa obra será "diminuir a distância existente entre os estudiosos de assuntos como a antropologia social, a filologia (lingüística) e o folclore, por um lado, e os psicanalistas, por outro". E nessa ênfase colocada na lingüística, não se poderia pensar, por analogia, na semiologia da lingüística saussuriana? O objetivo aqui será trabalhar no domínio da psicologia social segundo uma ótica psicanalítica, já que Freud afirma que pretenderá "aplicar o ponto de vista e as descobertas da psicanálise a alguns problemas não solucionados da psicologia social". Mais uma vez, não se poderia pensar nessa semiologia saussuriana como psicologia social?

Entretanto Freud indicará claramente que, em "Totem e Tabu", o ponto de partida de suas pesquisas não foi Saussure, mas, sim, Wundt e Jung, pois afirma: "Apresso-me em confessar que foi dessas duas fontes (Wundt e Jung) que recebi o primeiro estímulo para os meus próprios ensaios".

Se Wundt e Jung serviram de ponto de partida a Freud em "Totem e Tabu", eles serão, também, as referências nas quais ele se baseará para se diferenciar e, assim, marcar a identidade dessa obra. Mais precisamente, Freud dirá que de Wundt reterá sua proposição de efetuar uma pesquisa no domínio da psicologia coletiva, mas dele distanciando-se ao manter a ótica psicanalítica, que se opõe às hipóteses e métodos de trabalho de Wundt, que derivam da psicologia nãoanalítica.

No que concerne a Jung, Freud reconhecerá que sua idéia de um laço entre a psicanálise e a psicologia coletiva parecerá mesmo tê-lo influenciado, no entanto afirmará que de Jung se separará ao colocar a ênfase, em "Totem e Tabu", no estudo da psicologia coletiva, segundo uma ótica psicanalítica. Vale lembrar que Freud (1913/1974, p.20) diz que fará:"uma comparação entre a psicologia dos povos primitivos, como é vista pela antropologia social, e a psicologia dos neuróticos, como foi revelada pela psicanálise"; ao contrário do que fará Jung, que valorizará a psicologia individual explicada pela psicologia coletiva.

"Totem e Tabu", nesse sentido, constitui uma psicologia social vista segundo uma ótica psicanalítica, que se assemelha a uma "semiologia psicanalítica", lembrando a semiologia saussuriana, mas aparentemente sem possuir suas raízes no pensamento de Saussure (1916/1995a; 1916/1995b).

Por um lado, então,"Totem e Tabu" representa a primeira tentativa formal de Freud de realizar um estudo no domínio semiológico, num momento histórico contemporâneo à ocorrência dos cursos de lingüística geral de Saussure e da sua publicação, o que conduziu ao questionamento sobre uma possível influência saussuriana em Freud. Por outro lado, a preocupação de Freud em estabelecer um laço entre a psicologia social e a psicanálise, nesse contexto semiológico, parece ser muito anterior à publicação de "Totem eTabu" em 1913. Na carta 78 a Wilhelm Fliess, datada de 12 de dezembro de 1897, dezesseis anos antes dessa publicação e nove anos antes do primeiro ano dos cursos de lingüística geral de Saussure, Freud escreve:

... Você imagina o que podem ser os mitos endopsíquicos? Bem, eles são as últimas produções de minha atividade cerebral. A obscura percepção interna pelo sujeito de seu próprio aparelho psíquico suscita ilusões que, naturalmente, se encontram projetadas para fora e, de maneira característica, no futuro, num mais além. A imortalidade, a recompensa, todo o mais além, tais são as concepções de nossa psique interna... É uma psico-mitologia (3)" (Freud, 1950/1991, p.210). (Tradução nossa). 
O número"3" remete aqui a uma nota do editor:

A expressão 'mitos endopsíquicos' traduz os pensamentos que Freud exprimiu, de outra forma, em O poeta e a imaginação (1908e). Ele ali diz: 'No que se refere aos materiais, eles provêm do tesouro popular constituído pelos mitos, lendas e contos. $\mathrm{O}$ estudo destas criações psicológicas populares está longe de estar acabado e tudo leva a crer que os mitos, por exemplo, são muito verdadeiramente, vestígios deformados de fantasmas do desejo comuns a nações inteiras e que eles representam os sonhos seculares da jovem humanidade (Freud, 1950/ 1991, p.210.) (Tradução nossa).

A obra aqui referida, "O poeta e a imaginação", foi traduzida na primeira edição standard brasileira das obras psicológicas completas de Sigmund Freud por "Escritores criativos e devaneio" (Freud, 1908/1976).

Parece então que é no cruzamento dos domínios da psicologia social e da psicanálise e no contexto dos signos da semiologia que Freud (1950/ 1991; 1908/1976) se interrogou em particular sobre o sentido do signo "mito": "... Você imagina o que podem ser os'mitos endopsíquicos'?"Os"mitos endopsíquicos", a "psico-mitologia", serão assim valorizados como linguagem humana, "popular", atemporal, remetendo a um duplo fenômeno: social, por um lado, e inconsciente, por outro, posto que os mitos são"vestígios deformados de fantasmas (inconscientes) do desejo comuns a nações inteiras", e "eles representam os sonhos seculares da jovem humanidade" (grifo nosso).

Tal abordagem no Freud de 1908/1976, 1913/ 1974 e 1950/1991 parece lembrar o que propõe LéviStrauss (1958/1974, 2003) em "Antropologia Estrutural", no que concerne à valorização dos mitos, assim como sua compreensão como sendo os reveladores do inconsciente humano. Essas descobertas de Freud, que são destacadas agora neste trabalho, não reforçam a idéia da existência de universais da linguagem, especialmente no contexto dos mitos, que revelam a natureza humana profunda, o psiquismo inconsciente do homem?

Os mitos serão, então, valorizados por Freud (1913/1974) em "Totem e Tabu", obra que se pode compreender como sendo uma "psicologia social psicanalítica", ou, preferencialmente, uma "semiologia psicanalítica", na sua primeira produção literária formalmente proposta nesses domínios. E o próprio Freud considera essa obra uma de suas pesquisas favoritas, conforme assinala o editor inglês de "Totem e Tabu". Mas os mitos não serão aqui destacados sozinhos, pois aparecerão em evidência ao lado das religiões. Os mitos remeterão aqui as religiões. Mais precisamente, eles se situarão na origem das instituições religiosas. Para esclarecer essa idéia, serão discutidas a seguir algumas passagens dessa obra.

Freud (1913/1974, p.20) começará por definir sua amostra de estudo:"as tribos que foram descritas pelos antropólogos como sendo dos selvagens mais atrasados e miseráveis, os aborígenes da Austrália ... considerados uma raça distinta, sem apresentar relação física nem lingüística com seus vizinhos mais próximos, os povos melanésio, polinésio e malaio". Nessa sociedade primitiva, aparentemente sem vínculo com as sociedades atuais, o autor sublinha a inexistência de instituições religiosas e o papel do sistema de totemismo que as substitui. Ele escreve a esse propósito: "É altamente duvidoso que se Ihes possa atribuir qualquer religião moldada na adoração de seres superiores. ... Entre os australianos, o lugar das instituições religiosas e sociais que eles não têm é ocupado pelo sistema do 'totemismo'"' (Freud, 1913/1974, p.21).

À pergunta "o que é um totem?", Freud (1913/ 1974, p.21) responde, caracterizando-o, em primeiro lugar, como sendo o "antepassado comum do clã", e, em segundo lugar, e ao mesmo tempo, como sendo "seu espírito guardião e auxiliar, que lhe envia oráculos e, embora perigoso para outros, reconhece e poupa seus próprios filhos."

Mais adiante, Freud evocará as contribuições de Wundt para acrescentar uma outra caracterização do "totem": "sua significação mitológica". Ele escreverá então:

O animal totêmico é também geralmente considerado o animal ancestral do grupo em questão. 'Totem' é, por um lado, um nome de grupo, um indicativo de ancestralidade. Sob o último aspecto, possui também uma significação mitológica (Freud, 1913/1974, p.131).

Esse "totem", enquanto "mito", será, então, regido pelas leis da mitologia e, assim, terminará por se transformar em "tabu". A esse respeito, mais uma vez será em Wundt que Freud se apoiará para escrever: 
Mas como ocorreu essa cisão? Através da transplantação, é o que nos diz Wundt, dos regulamentos do tabu, da esfera dos demônios para a esfera da crença em deuses. [lbid., 311.] O contraste entre'sagrado'e'impuro'coincide com uma sucessão de dois períodos da mitologia. O mais antigo desses dois períodos não desapareceu completamente quando o segundo foi alcançado, mas persistiu no que foi considerado como uma forma inferior e finalmente desprezível. [lbid., 312] É uma lei geral da mitologia, afirma ele, que uma fase que tenha passado, pelo próprio motivo de ter sido superada e impelida para baixo por uma fase superior, perdura numa forma inferior ao lado da posterior, de modo que os objetos de sua veneração se transmudam em objetos de horror" (Freud, 1913/1974, p.45).

Compreende-se, assim, que uma lei mitológica de transformação faria dos totens (mitos) originários de um primeiro tempo, os tabus de um segundo tempo. Mas, ocorreria também um fenômeno oposto, a saber: a ausência da transformação, a conservação do mito.

O conjunto desses dois aspectos remete aparentemente a uma contradição. Mais precisamente, se, por um lado, os totens são mitos originários, objetos de veneração que, apesar das aparências, não cessam nunca de existir, permanecem vivos ainda que escondidos "no que foi considerado como uma forma inferior e finalmente desprezível" (o tabu), parece que, por outro lado, os totens, como"objetos de ... veneração, se transmudam em objetos de horror" (os tabus).

Essa aparente contradição da lei mitológica de transformação lembra a semântica como estudo das mudanças de significação e, mais precisamente, o que Saussure (1916/1995b, p.89) chama de aparente contradição da língua, quando fala desse fenômeno de transformação semântica como remetendo, ao mesmo tempo, à imutabilidade e à mutabilidade do signo (Bento, 1996).

No que concerne às religiões, tal como são concebidas atualmente como cultos rendidos a Seres superiores, às suas restrições morais e às suas leis, elas pareceriam ter aparecido com os tabus e possuir, como eles, uma origem recalcada, oculta, nos "totens-mitos".

A propósito dessa semelhança entre religiões e tabus, Freud, fazendo uma comparação entre a psicologia das neuroses e as grandes produções sociais, acabará por aproximar as neuroses obsessivas das religiões e dos tabus, o que não se fará, evidentemente, sem reforçar o laço entre esses dois últimos.
Compreende-se, assim, que os tabus constituem uma característica comum das neuroses obsessivas e das religiões. Freud escreverá a esse respeito:

Nas formas que assume, o tabu assemelha-se muito estreitamente ao medo de contato do neurótico, com a sua 'fobia de contato'. ...

Esta simples comparação entre o tabu e a neurose obsessiva é suficiente para fazer-nos compreender a natureza da relação entre as diferentes formas de neuroses e instituições culturais e perceber como o estudo da psicologia das neuroses é importante para a compreensão do desenvolvimento da civilização.

As neuroses, por um lado, apresentam pontos de concordância notáveis e de longo alcance com as grandes instituições sociais, a arte, a religião e a filosofia. Mas, por outro lado, parecem como se fossem distorções delas. Poder-se-ia sustentar que um caso de histeria é a caricatura de uma obra de arte, que uma neurose obsessiva é a caricatura de uma religião e que um delírio paranóico é a caricatura de um sistema filosófico" (Freud, 1913/1974, p.95).

No que concerne ao aparecimento das religiões, posteriormente aos mitos, Freud aborda essa questão no contexto de uma psicologia do desenvolvimento dos sistemas intelectuais, das concepções do mundo, na história do homem:

A raça humana, se seguirmos as autoridades no assunto, desenvolveu, no decurso das eras, três desses sistemas de pensamento - três grandes representações do universo: animista (ou mitológica), religiosa e científica. Dessas, o animismo, o primeiro a ser criado, é talvez o mais coerente e completo e o que dá uma explicação verdadeiramente total da natureza do universo (Freud, 1913/1974, p.99).

A ênfase é aqui colocada na origem do pensamento humano, que é o sistema intelectual animista. Esse, remetendo aos mitos, "é talvez o mais coerente e completo" (dos sistemas intelectuais), porque ele "dá uma explicação verdadeiramente total da natureza do universo". É preciso entender aqui uma valorização dos mitos, na medida em que eles seriam, por um lado, originários, e, por outro, por que anteriores aos tabus è̀s religiões, seriam também a expressão de um homem que, livre dos tabus, não mais sofreria o medo constrangedor que entrava a manifestação de seu pensamento.

A propósito da valorização desses mitos, assim como da compreensão deles como pensamento criativo, livre, originário, atemporal e revelador da natureza humana, Freud evocará de novo Wundt: 
Ao examinar o fato de as mesmas idéias animistas haverem surgido entre os povos mais variados e em todos os períodos, Wundt $(1906,154)$ declara que 'elas constituem o produto psicológico necessário de uma consciência mitocriadora ... e assim, neste sentido, o animismo primitivo deve ser encarado como a expressão espiritual do estado natural do homem, até onde é acessível à nossa observação' (Freud, 1913/1974, p.99).

Como foi visto, tal liberdade de pensar, de exprimir-se como humano, será, além disso, caracterizada por Freud (1950/1991, p.210) como liberdade para projetar-se "para fora e, de maneira característica, no futuro, no mais além" (tradução nossa), e ele qualificará essa projeção de "criação psicológica popular" (Freud, 1908/1976). Aqui, em "Totem e Tabu", Freud retomará essa idéia, apoiando-se dessa vez no que Hume fala sobre o animismo:

A justificativa para a atribuição de vida aos objetos inanimados já fora enunciada por Hume em sua Natural History of Religion [Seção III]: 'Existe uma tendência universal entre os humanos para conceber todos os seres à sua semelhança e transferir a todos os objetos as qualidades que Ihes são familiares e das quais se achem intimamente conscientes (Freud, 1913/1974, p.99).

Vê-se, assim, que as religiões, como cultos rendidos aos Seres superiores e às restrições morais (em oposição aos mitos, ao animismo, nos quais se observa o'culto'livre, sem restrições intelectuais, do homem aos seus pares), aparecem apenas num segundo tempo da história da raça humana. Mas, da mesma forma que os tabus, as religiões têm a sua origem num tempo anterior, no tempo dos "totens-mitos" que, recalcados, tornaram-se, então, "inconscientes" ao longo desse segundo tempo religioso. No que concerne a essa origem, foi visto em Freud (1913/1974, p.45) que os tabus (que caracterizam o pensamento religioso) se fundam, de fato, nas transformações dos mitos (totens). Mas convém acrescentar o que Freud escreve no seu prefácio de "Totem e Tabu": "O totemismo ... - uma instituição i⿱宀 social-religiosa que foi há muito tempo relegada como 眊 realidade e substituída por formas mais novas" (Freud, 帘 1913/1974, p.18)

Na tradução francesa dessa passagem, pode-se ler mais claramente que "o totemismo ... é uma instituição desde muito tempo desaparecida e substituída por novas formas religiosas e sociais" (Freud, 1913/1965, p.8) (tradução nossa). Falar de novas formas religiosas não parece ser a mesma coisa que dizer que os "totens-mitos" correspondiam "às antigas formas religiosas?" A propósito dessa forma de religião, antiga e entre aspas, no totemismo, pode-se citar uma passagem de Freud na qual, no quarto e último capítulo de "Totem e Tabu", ele resume essa idéia como uma espécie de introdução, mas também de conclusão:

No primeiro desta série de ensaios, familiarizamonos com o conceito de totemismo. Aprendemos que o totemismo é um sistema que ocupa o lugar da religião entre certos povos primitivos da Austrália, da América e da África e provê a base de sua organização social (Freud, 1913/1974, p.125).

Pode-se agora compreender melhor em que sentido se disse acima que, em "Totem e Tabu", os mitos seriam valorizados ao lado das religiões. A esse propósito, convém lembrar uma citação de Freud (1913/ 1974, p.45) destacada acima:"É uma lei geral da mitologia, afirma ele, que uma fase que tenha passado (a do totemismo, dos mitos, do animismo), pelo próprio motivo de ter sido superada e impelida para baixo (recalcada) por uma fase superior (a da religião, do tabu), perdura numa forma inferior ao lado da posterior". Parece que a idéia dos mitos ao lado das religiões é perfeitamente análoga àquela do "totem" ao lado do "tabu" até no título da obra em questão (Freud, 1913/1974).

\section{Considerações Finais}

Acredita-se ter sido possível atingir o objetivo deste trabalho, pois acima foi caracterizado brevemente o que se compreende como sendo os fundamentos freudianos para uma semiologia psicanalítica, e, também, para o método de revisão de literatura em psicanálise. Tais fundamentos foram encontrados particularmente em "Totem e Tabu", a primeira pesquisa de Freud nesse domínio da semiologia psicanalítica e, também, uma das mais importantes na sua obra como um todo. Ainda que o pai da psicanálise não tenha se utilizado da expressão "semiologia psicanalítica"na obra em questão, parece ter efetivamente ali feito o que se entendeu como sendo a prática da semiologia psicanalítica de dois signos: "totem" e "tabu". 
Por semiologia psicanalítica foi entendido neste trabalho o estudo de signos ("signo" na definição de Saussure como remetendo àquilo que une um significado a um significante) no seu contexto lingüístico originário (como, por exemplo, os mitos, os escritos clássicos, etc.) e recalcado nas aparições da língua da atualidade. Nessa valorização do estudo dos signos, que poderiam ser "conceitos", em sua aparição nos textos clássicos, vê-se a ênfase colocada no método de revisão de literatura.

Por um lado, pode-se concluir que esse exame da abordagem freudiana em "Totem e Tabu" pareceu ter confirmado os achados de outras pesquisas. Foram elas: 1) A semiologia saussuriana: em Bento (1996, item 1.1); e 2) Lévi-Strauss: sua antropologia estrutural e sua abordagem dos mitos como linguagem do domínio da língua, da fala e de um sistema universal de signos, em Bento (1996, item 1.1.3). Dessa forma, foi encontrado em Freud (1913/1974) e em Saussure (1916/1995a, 1916/ 1995b) o destaque à importância de uma pesquisa semiológica radical, valorizando, assim, as origens dos signos. Também foi possível achar uma aproximação entre Freud (1913/1974) e Lévi-Strauss (1958/1974, 2003), ambos os autores parecendo buscar os universais da linguagem - especialmente nos totens e nos mitos de um primeiro tempo, esses reveladores da natureza humana mais profunda, do psiquismo inconsciente do homem, da verdade humana imutável, atemporal e originária.

Entendeu-se neste estudo "natureza humana mais profunda, psiquismo inconsciente do homem e verdade humana imutável" a partir das contribuições de Saussure (1995). Embora não tenha diretamente postulado, Saussure parece conceber "universais da linguagem" reveladores da natureza humana profunda. Mesmo classicamente conhecido pela "equação": linguagem é igual a língua mais fala, pelo destaque dado ao relativo, ao arbitrário do signo, aos sistemas particulares de signos (a língua e a fala), Saussure (1916/ 1995b, p.82) valorizará também os signos universais quando admite a existência simultânea de "signos inteiramente naturais", do "símbolo não ser jamais completamente arbitrário", de "um rudimento de vínculo natural entre o significante e o significado". Além disso, na abordagem da semântica, Saussure (1916/ 1995b, p.89) dirá que "o que domina, em toda alteração (do signo), é a persistência da matéria velha". Finalmente, tratar-se-á em Saussure de propor uma abordagem psicológica, pondo então em evidência a representação, no lugar da coisa material em si, como se pode ver em sua definição de signo (Saussure, 1916/1995b, p.80).

Não se poderia pensar que aquilo que está presente no homem sob a forma de universais lingüísticos naturais, na origem das transformações subseqüentes dos signos, recalcado, portanto, na aparência atual do signo, também estaria presente tanto no sujeito do inconsciente (fenômeno social) quanto no inconsciente do sujeito (fenômeno individual), inconsciente esse objeto por excelência da investigação psicanalítica? Se sim, não se poderia então afirmar que o método semiológico justificaria e fundamentaria a revisão de literatura como método de pesquisa, também em psicanálise? Não seria essa semiologia radical presente no pensamento de Saussure que depuraria os ditos universais da linguagem reveladores da natureza humana lingüística inconsciente?

Esse mesmo exame de Freud (1913/1974) permitiu que se percebesse que é importante também, num segundo tempo, orientar igualmente a pesquisa semiológica para os tabus e para as religiões, que se mantêm, relembrando, ao lado dos mitos.

Enfim, pode-se resumir a conclusão principal: para manter uma ótica psicanalítica freudiana num estudo semiológico, será necessário colocar a ênfase, como fazFreud (1913/1974) em "Totem eTabu", na análise radical dos universais da linguagem, esses reveladores da natureza humana mais profunda, do psiquismo inconsciente do homem, extraindo tais universais, num primeiro tempo, dos totens e mitos, mas também, num segundo tempo, dos tabus e das religiões. Tal estudo demandando de alguma maneira o exame de "escritos" não pareceria, assim, justificar o método de revisão de literatura em psicanálise?

\section{Referências}

Bento, V. E. S. (1996). La passion amoureuse "toxique": une approche psychanalytique à partir de la sémiologie et du narcisisme chez Freud. Thèse de doctorat pas-publié, Laboratoire de Psychopathologie Fondamentale et Psychanalyse, Université Paris 7. 
Bento, V. E. S. (2006). Seria a semiologia de Saussure fundamento e justificativa para o método de pesquisa de revisão de literatura em psicanálise? Estudos de Psicologia, 23 (4), 407-423.

Ferreira, A. B. H. (1975). Novo dicionário da língua portuguesa. Rio de Janeiro: Nova Fronteira.

Freud, S. (1976). Escritores criativos e devaneio. In S. Freud. Edição standard brasileira das obras psicológicas completas de Sigmund Freud (Vol.9, pp.145-158). Rio de Janeiro: Imago. (Originalmente publicado em 1908).

Freud, S. (1965). Totem et tabou. France: Payot. (Originalement publié en 1913).

Freud, S. (1974). Totem e tabu. In S. Freud. Edição standard brasileira das obras psicológicas completas de Sigmund Freud (Vol.13, pp.11-191). Rio de Janeiro: Imago. (Originalmente publicado em 1913).
Freud, S. (1991). Lettre 78 à Wilhelm Fliess (12/12/1897). In S. Freud. La naissance de la psychanalyse (6a.ed., pp.210-1). Paris: PUF. (Originalement publié en 1950).

Lalande, A. (1996). Vocabulário técnico e crítico da filosofia. São Paulo: Martins Fontes.

Lévi-Strauss, C. (1974). Anthropologie structurale. Paris: Plon. (Originalement publié en 1958).

Lévi-Strauss, C. (2003). Antropologia estrutural (6a. ed.). Rio de Janeiro: Tempo Brasileiro.

Saussure, F. (1995a). Cours de linguistique générale. Paris: Payot \& Rivages. (Originalement publié en 1916).

Saussure, F. (1995b). Curso de lingüística geral. São Paulo: Cultrix. (Originalmente publicado em 1916).

Recebido em: 29/8/2006

Versão final reapresentada em: 29/8/2006

Aprovado em: 7/11/2006 